\title{
High-Flow Nasal Cannula Devices: Noisier Than We Realize
}

Noise is unwanted sound. In rooms where patients are treated or observed, the World Health Organization advises that average sound levels should not exceed $35 \mathrm{~dB}$ during the day and $30 \mathrm{~dB}$ at night. ${ }^{1}$ During the past 50 years, with more sound-producing devices coming into widespread use, daytime sound levels in hospitals have been annually increasing by $0.38 \mathrm{~dB} /$ year, and nighttime levels have increased by $0.42 \mathrm{~dB} /$ year. ${ }^{2}$ Major sources of ICU sound include conversation, equipment alarms and monitoring sounds, caregiving activities, phones and pagers, audio sources and television, and door impacts and falling objects. Rather than quieting the ICU, technological advance has brought more noise. For example, a ventilator alarm is as loud as a vacuum cleaner, raising the ICU peak sound level to $85 \mathrm{~dB}$ or more, and this may occur on average $>16$ times $/ \mathrm{h} .{ }^{3}$ In ICUs, where $>30 \%$ of patients are already susceptible to confusion or delirium, noise contributes greatly to disrupted, fragmented, and insufficient sleep, which could trigger delirium. Improving sleep quality through noise reduction is a priority issue.

Compared with alarms, conversations between the ICU staff, and other occasional sounds, the everyday background noise of building or life-support equipment may receive less attention. We know, however, that severe and prolonged noise exposure causes permanent hearing loss in preterm neonates. ${ }^{4}$ Noise intensities in the oral cavity during nasal CPAP have been reaching $88.6 \mathrm{~dB},{ }^{4}$ higher than the acceptable level of $45 \mathrm{~dB}$ in neonatal ICUs. ${ }^{5}$ In adults, Cavaliere et $\mathrm{al}^{6}$ assessed noise intensity during noninvasive ventilation (NIV) with different types of interface: in helmets, noise levels near the right ear always exceeded $100 \mathrm{~dB}$ but were within $70 \mathrm{~dB}$ during NIV with nasal or face masks. Surely, this contributes to the high rate $(37 \%)$ of delirium that we observed in NIV patients.

Associated with lower morbidity and mortality than NIV, high-flow nasal cannula (HFNC) oxygen therapy is in-

\footnotetext{
The authors have disclosed no conflicts of interest.
}

Correspondence: Taiga Itagaki MD PhD, Emergency and Critical Care Medicine, Tokushima University, 3-18-15 Kuramoto, Tokushima, 7708503 Japan. E-mail: taiga@tokushima-u.ac.jp.

DOI: $10.4187 /$ respcare.06155 creasingly used as an alternative means of noninvasive respiratory support. ${ }^{7,8}$ In this issue of RESPIRATORY CARE, Kubo et $\mathrm{al}^{9}$ report the results of digitally measuring noise

See the Original Study on Page 267

levels of 3 different types of HFNC devices at different levels of total flow $(30,40,50$, and $60 \mathrm{~L} / \mathrm{min})$ and $\mathrm{F}_{\mathrm{IO}_{2}}$ $(0.4,0.5$, and 0.9$)$. The merit of this study is that, despite current concerns for safety and comfort, it is the first to investigate noise production during $\mathrm{HFNC}$ in adults rather than neonates. ${ }^{10}$ Its results suggest that HFNC delivered by Venturi effect was the noisiest and HFNC delivered by turbine was the quietest at $\mathrm{F}_{\mathrm{IO}_{2}}<0.6$. With Venturi delivery, noise levels were reduced when an air filter was used, but filtering had no such effect with HFNC delivered by an airoxygen blender. The authors propose 2 ways to decrease noise exposure during HFNC: choose less noisy modalities and, where effective, use an air filter as a silencer.

Although this study has added to the body of evidence on noise generated during HFNC, uncertainties remain due to the experimental design of the bench study. Noise levels were lower than those found in a neonatal model, ${ }^{10}$ which recorded up to $90 \mathrm{~dB}$ measured in the oral cavity of the manikin of a newborn; this was probably because the nasal prong, the major noise source, was distant from the sound meter. More accurate simulation of clinical practice using manikins, model lungs, and different-sized nasal prongs may provide more trustworthy results. Moreover, during HFNC, bone conducts sound to the inner ear, and this conduction causes discrepancies between measured and perceived noise levels. Human studies including subjective evaluation of noise intensity may reveal the extent to which HFNC increases patient discomfort and how the use of different HFNC devices and interfaces, as well as silencers and earplugs, affects noise.

Whereas noise generated in HFNC systems may well be lower than during NIV, it is clear that noise during HFNC far exceeds recommended levels. Technological advance should result in greater comfort for recovering patients. Meanwhile, during respiratory care, providers should endeavor to minimize the exposure of patients to noise, both by avoiding unnecessary use of HFNC and, generally, by finding beneficial ways to reduce noise 


\section{EDITORIALS}

levels and patient discomfort. No matter how promising a particular treatment may be, the local efficacy of ventilation may be counteracted by the overall human response.

\section{Taiga Itagaki MD PhD Masaji Nishimura MD PhD Emergency and Critical Care Medicine Tokushima University Tokushima, Japan}

\section{REFERENCES}

1. Berglund B, Lindvall T, Schwela DH. Guidelines for community noise. Geneva: World Health Organization; 1999.

2. Busch-Vishniac IJ, West JE, Barnhill C, Hunter T, Orellana D, Chivukula R. Noise levels in Johns Hopkins Hospital. J Acoust Soc Am 2005;118(6):3629-3645.

3. Darbyshire JL, Young JD. An investigation of sound levels on intensive care units with reference to the WHO guidelines. Crit Care 2013;17(5):R187.
4. Karam O, Donatiello C, Van Lancker E, Chritin V, Pfister RE, Rimensberger PC. Noise levels during nCPAP are flow-dependent but not device-dependent. Arch Dis Child Fetal Neonatal Ed 2008; 93(2):F132-F134.

5. American Academy of Pediatrics. Noise: a hazard for the fetus and newborn: Committee on Environmental Health. Pediatrics 1997; 100(4):724-727.

6. Cavaliere F, Conti G, Costa R, Proietti R, Sciuto A, Masieri S. Noise exposure during noninvasive ventilation with a helmet, a nasal mask, and a facial mask. Intensive Care Med 2004;30(9):1755-1760.

7. Nishimura M. High-flow nasal cannula oxygen therapy in adults: physiological benefits, indication, clinical benefits, and adverse effects. Respir Care 2016;61(4):529-541.

8. Frat JP, Thille AW, Mercat A, Girault C, Ragot S, Perbet S, et al. High-flow oxygen through nasal cannula in acute hypoxemic respiratory failure. N Engl J Med 2015;372(23):2185-2196.

9. Kubo T, Nakajima H, Shimoda R, Seo T, Kanno Y, Kondo T, Tamai S. Noise exposure from high-flow nasal cannula oxygen therapy: a bench study on noise reduction. Respir Care 2018; 63(3):267-273

10. König K, Stock EL, Jarvis M. Noise levels of neonatal high-flow nasal cannula devices: an in-vitro study. Neonatology 2013;103(4): 264-267. 